\title{
Separation of Stratiform and Convective Rain Types Using Data from an S-Band Polarimetric Radar: A Case Study Comparing Two Different Methods ${ }^{\dagger}$
}

\author{
Merhala Thurai $^{1, *}$, David Wolff ${ }^{2} \mathbb{C}$, David Marks ${ }^{2,3}$, Charanjit Pabla ${ }^{2,3}$ and Viswanathan Bringi ${ }^{1}$ \\ 1 Department of Electrical and Computer Engineering, Colorado State University, Fort Collins, CO 80523, USA; \\ bringi@engr.colostate.edu \\ 2 NASA GSFC Wallops Flight Facility, Wallops Island, VA 23337, USA; david.b.wolff@nasa.gov (D.W.); \\ david.a.marks@nasa.gov (D.M.); charanjit.s.pabla@nasa.gov (C.P.) \\ 3 Science Systems and Applications, Inc., Lanham, MD 20706, USA \\ * Correspondence: merhala@engr.colostate.edu; Tel.: +1-970-491-7678 \\ + Presented at the 4th International Electronic Conference on Atmospheric Sciences, 16-31 July 2021; \\ Available online: https:/ / ecas2021.sciforum.net.
}

check for updates

Citation: Thurai, M.; Wolff, D.;

Marks, D.; Pabla, C.; Bringi, V.

Separation of Stratiform and

Convective Rain Types Using Data

from an S-Band Polarimetric Radar: A

Case Study Comparing Two Different

Methods. Environ. Sci. Proc. 2021, 8, 1

https://doi.org/10.3390/ecas2021-

10358

Academic Editor: Anthony R. Lupo

Published: 22 June 2021

Publisher's Note: MDPI stays neutral with regard to jurisdictional claims in published maps and institutional affiliations.

Copyright: (c) 2021 by the authors. Licensee MDPI, Basel, Switzerland. This article is an open access article distributed under the terms and conditions of the Creative Commons Attribution (CC BY) license (https:// creativecommons.org/licenses/by/ $4.0 /$ )

\begin{abstract}
Data from an S-band polarimetric radar located at a mid-latitude, coastal location are used to compare two different methods for identifying stratiform and convective rain regions. The first method entails the retrievals of two (main) parameters of the rain drop size distributions using the radar reflectivity and the differential reflectivity. The second technique is a well-known texture-based method which utilizes the radar reflectivity and its spatial variability. A widespread event with embedded line convection was used as a test case. The two methods were compared using $500 \mathrm{~m}$ by $500 \mathrm{~m}$ pixel resolution gridded data constructed from the radar volume scans. Only $12 \%$ of the pixels showed disagreement between the two methods.
\end{abstract}

Keywords: stratiform-convective rain separation; rain drop size distribution; S-band polarimetric radar

\section{Introduction}

There are several different methods available in the literature to classify and separate stratiform and convective rain types. These include (a) the use of radar reflectivity 'texture' from weather radar scans, e.g., [1], (b) using ground in situ measurements including surface disdrometers, e.g., [2,3], (c) using profiler observations, e.g., [4], and (d) based on the magnitude of up- and downdrafts, e.g., [5]. Additionally, the estimated or retrieved characteristics of rain drop size distributions (DSD) have also been used to identify the two rain types [6,7], and were compared with the reflectivity-texture based method in [8,9] using C-band radar observations in Darwin, Australia, which is a tropical region. In this paper, we perform similar comparisons between the same two methods (i.e., between the reflectivity texture-based method and the DSD-based method), but in the current study, we utilize data from an S-band polarimetric radar (NPOL, e.g., [10]) at a mid-latitude coastal region, namely Wallops Island, Delmarva peninsula, USA.

In a very recent paper [11], the DSD-based separation method was tested using data from two collocated disdrometers based at the Wallops site. The two disdrometers were (i) a Meteorological Particle Spectrometer (MPS; [12]), which provided accurate measurements of drop concentrations for small and tiny drops (particularly for drop diameters below $1.2 \mathrm{~mm}$ ), and (ii) a 2D video disdrometer (2DVD; $[13,14]$ ) for drop concentrations above $1 \mathrm{~mm}$. By combining both sets of measurements, the full DSD spectra were constructed and a rain-type classification was made using 1- and 3-min DSDs. For each of these DSDs, the mass-weighted mean diameter, $D_{m}$, and the normalized intercept parameter, $N_{W}$, were derived, and depending on where each point was in the $N_{W}$ versus $D_{m}$ domain, the corresponding rain type was determined. The classification was then 'visually' compared 
against RHI scans from the NPOL radar, made over the disdrometer site. Over $20 \mathrm{~h}$ of 1and 3-min DSD data (and the corresponding RHI scans) were used for verification.

As a follow on, in this paper, we examine the application of the same basic technique to the S-band NPOL radar data. An improved retrieval method is used to estimate $N_{W}$ and $D_{m}$ from the radar reflectivity and differential reflectivity measurements. Gridded data from -60 to $+60 \mathrm{~km}$ along north-to-south and east-to-west are used at various altitudes from $1000 \mathrm{~m}$ to $3000 \mathrm{~m}$ above sea level, in steps of $500 \mathrm{~m}$. The (constant-altitude) gridded data were constructed from the NPOL radar volume scans taken during a relatively wide-spread event with embedded line convection which passed over the Wallops site on 30 April 2020. The lowest gridded level was used for pixel-by-pixel comparison against the reflectivity texture-based method from [1].

\section{Estimating $N_{W}$ and $D_{m}$ from NPOL Radar Data}

The equations used for retrieving (or estimating) $N_{W}$ and $D_{m}$ from the NPOL reflectivity and differential reflectivity $\left(Z_{h}\right.$ and $Z_{d r}$, respectively) were previously given in [11], and hence, they are briefly described here. The estimation of $D_{m}$ is a two-step procedure, the first step involving the estimation of an intermediary parameter, $D_{m}{ }^{\prime}$, which depends on two chosen reference moments [15]. If we denote these as $M_{i}$ and $M_{j}$, then $D_{m}{ }^{\prime}$ is given by:

$$
D_{m}^{\prime}=\left(\frac{M_{j}}{M_{i}}\right)^{\frac{1}{(j-i)}}
$$

At S-band, simulations have shown that $D_{m}{ }^{\prime}$ can be directly estimated from $Z_{d r}$ within reasonable/acceptable accuracy. Figure 1a shows the simulation points using 3-min measured DSDs (i.e., full DSD spectra, but from two different locations, Huntsville, Alabama, which is a sub-tropical region, and Greeley, Colorado, which is a mid-latitude continental climate) as well as the fitted curve, given by:

$$
D_{m}^{\prime}=0.0822 Z_{d r}^{3}-0.4841 Z_{d r}^{2}+1.7515 Z_{d r}+0.628
$$

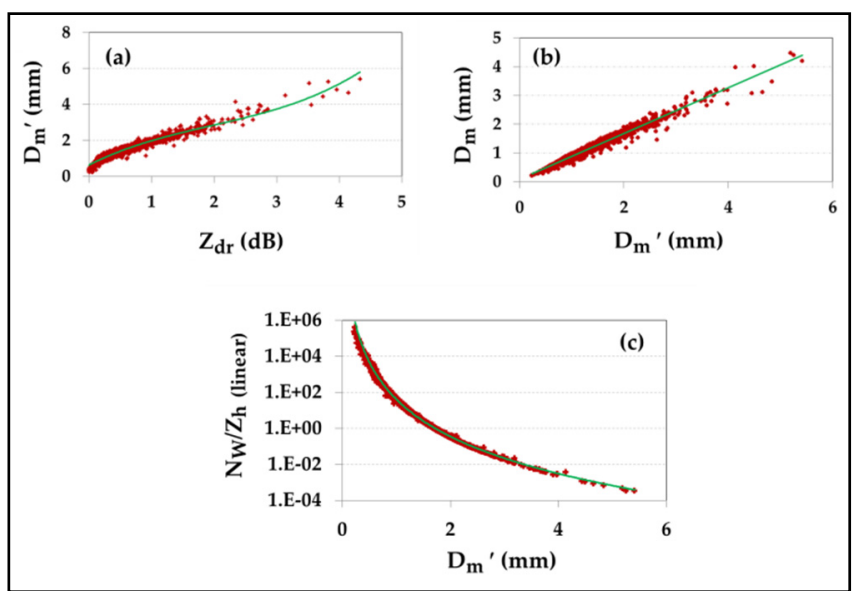

Figure 1. S-band simulation results of (a) $D_{m}{ }^{\prime}$ versus $Z_{d r} ;$ (b) $D_{m}$ with $D_{m}{ }^{\prime} ;$ (c) $N_{W} / Z_{h(l i n e a r)}$ versus $D_{m}{ }^{\prime}$.

Next, we determine $D_{m}$ from $D_{m}{ }^{\prime}$. Once again, S-band simulations have shown that this can be done within good accuracy, as shown in panel (b) of Figure 1. The fitted curve is given by:

$$
D_{m}=0.7977 D_{m}^{\prime}+0.0883
$$

Note that both panels (a) and (b) show a monotonic increase; hence, no ambiguity will arise when using Equations (2) and (3). 
The third and final step is to determine $N_{W}$. As shown in [11], $N_{W}$ is given by:

$$
N_{W}=\left(\frac{4^{4}}{6}\right) N_{0}^{\prime}
$$

where:

$$
N_{0}{ }^{\prime}=M_{i}^{\frac{(j+1)}{(j-i)}} M_{j}^{\frac{(i+1)}{(i-j)}}
$$

To derive $N_{W}$, we need to make use of both the retrieved $D_{m}$ as well as the radar reflectivity. Panel (c) shows the variation of $N_{W} / Z_{h(\text { linear })}$ versus $D_{m}$, where $Z_{h(\text { linear })}$ is the radar reflectivity in linear units. The fitted curve (monotonic decrease) is given by:

$$
\frac{N_{W}}{Z_{h(\text { linear })}}=39.446 D_{m}^{\prime}-6.839
$$

In summary, Equations (2), (3), and (6) are used to estimate $N_{W}$ and $D_{m}$ for each of the gridded pixels from the S-band scans.

\section{NPOL Data and the Event on 30 April 2020}

On 30 April 2020, a slow-moving cold front passed over the WFF region. A NW/SEoriented line of strong convection with heavy rain moved through the region. Reflectivity within the line was as high as $60 \mathrm{dBZ}$ in areas. The convective line was embedded in stratiform with reflectivity in the range 25 to $35 \mathrm{dBZ}$. As recorded in NASA rain gauges at Wallops, approximately $20 \mathrm{~mm}$ accumulated between 19 to $22 \mathrm{~h}$ UTC, the majority of which fell within $30 \mathrm{~min}$ associated with the convective line.

Figure 2a,b show the gridded data constructed from the volume scans taken at 21:05 UTC: (a) reflectivity and (b) differential reflectivity, both at $1000 \mathrm{~m}$ above sea level with a pixel resolution of $500 \mathrm{~m} \times 500 \mathrm{~m}$. The line convection shows reflectivities as high as 55 to $60 \mathrm{dBZ}$ and differential reflectivities of $>2 \mathrm{~dB}$ in some regions. Note also that, at azimuths of around $170^{\circ}$, some beam-blockage problems exist (which need to be omitted from the classification procedure).

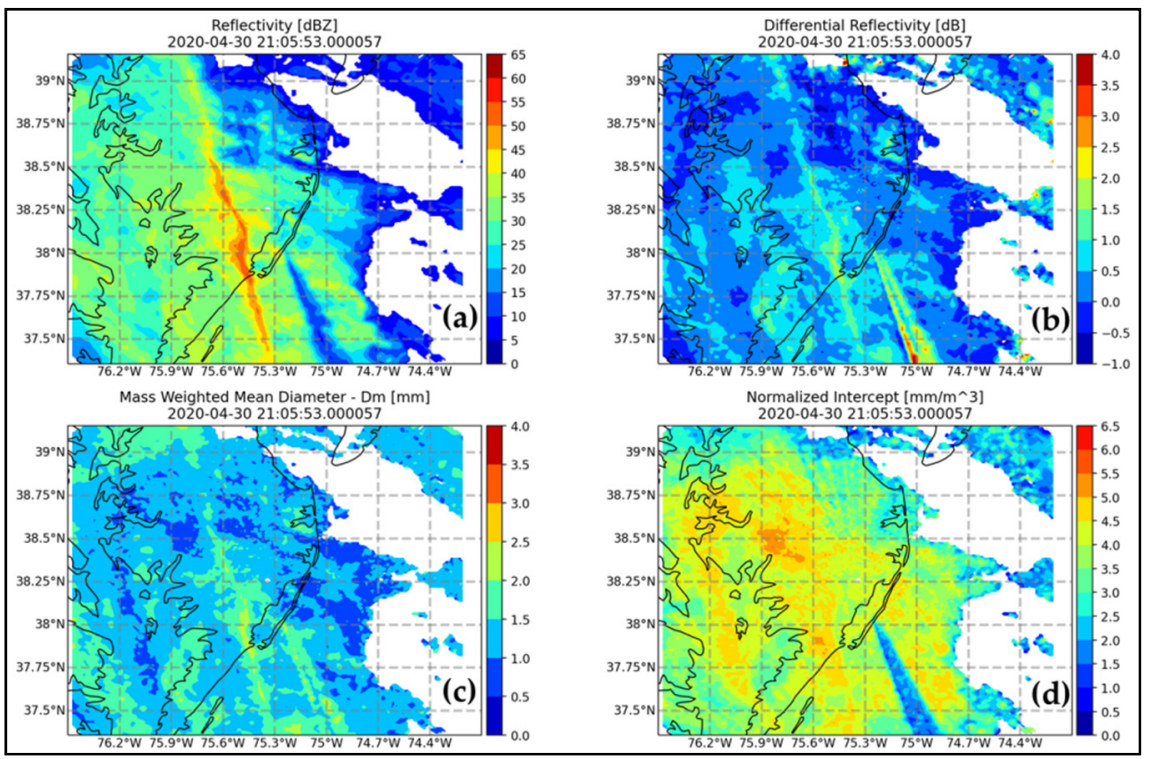

Figure 2. NPOL gridded data at $1000 \mathrm{~m}$ altitude with $500 \mathrm{~m}$ by $500 \mathrm{~m}$ pixel resolution; (a) $Z_{h}$; (b) $Z_{d r}$; (c) estimated $D_{m} ;\left(\right.$ d) estimated $N_{W}$.

Panels (c) and (d) of Figure 2 show the estimated $N_{W}$ and $D_{m}$, respectively, derived using Equations (2), (3), and (6). Once again, the effect of beam-blockage at $\sim 170^{\circ}$ azimuth 
is evident in the retrievals. Within the line convection itself, $D_{m}$ values $>2 \mathrm{~mm}$ are seen in some regions.

\section{Rain Type Classification}

The gridded data ranging from $-60 \mathrm{~km}$ to $+60 \mathrm{~km}$ both in the north-south and the eastwest directions were extracted and the classification based on the $N_{W}-D_{m}$ values for each pixel was determined. As mentioned in [11], "a simple 'index' parameter, $i$ (empirically derived), was used to indicate whether the $N_{W}$ versus $D_{m}$ lie above or below the separation line". The value of $i$ for each pixel is given by:

$$
i=\log _{10}\left(N_{W}^{e s t}\right)-\log _{10}\left(N_{W}^{s e p}\right)
$$

where:

$$
\log _{10}\left(N_{W}^{s e p}\right)=c_{1} D_{m}^{e s t}+c_{2}
$$

In Equation (7), $N_{W}{ }^{\text {est }}$ is the estimated $N_{W}$ for the specific pixel and $D_{m}{ }^{\text {est }}$ the (corresponding) estimated $D_{m}$. Note that, in [11], Equations (7) and (8) were applied to disdrometer-based DSD data. Note also that "values of $c_{1}$ and $c_{2}$ may vary somewhat depending on the location, but to be consistent with our previous study, they were set to -1.682 and 6.541 , respectively". If, for a given pixel, $i$ is negative, it is categorized as stratiform rain, and when $i$ is positive, it is categorized as convective rain. Additionally, we introduce another category, namely, 'Mixed' (or Uncertain/Transition), when the magnitude of $i$ is less than 0.05 , i.e., $-0.05 \leq i \leq 0.05$. Such a category was initially introduced in [16] based on measurements from large squall lines with trailing stratiform rain. The disdrometer measurements showed that they were able to identify the convective line and the stratiform rain areas quite easily but there was a transition region between the convective and the stratiform which showed a different $Z-R$ than for pure convection versus pure stratiform. We use the term 'transition' here even if the storm type does not belong to the squall lines described in [16]. Based on the latter, a third category was introduced in [8], using the C-band CPOL radar data from Darwin, Australia (although in that study, a wider range for $i$ was used, viz. $-0.1 \leq i \leq 0.1$ ). The third category has been termed transition, mixed or uncertain.

Panel (a) of Figure 3 shows the classification for the $1000 \mathrm{~m}$ altitude gridded data in Figure 2. The orange/red color represents convective rain category, and the cyan/turquoise color for stratiform rain. The purple color represents the mixed category, which appears to be predominantly in regions surrounding convective rain areas. By comparison, panel (b) of Figure 3 shows the texture-based classification from the texture-based method. Both plots show somewhat similar features, but to compare the classifications on a pixel-to-pixel basis, we show in panel (c) the matched/mismatched pixels. The colors represent the following:
Light blue/cyan
Red
when both methods classify as stratiform rain.
Orange
when both methods classify as convective rain.
Green when the DSD-based method classifies as
when the DSD-based method classifies as convective rain and the texture method as stratiform rain.
Purple when the DSD-based method classifies as mixed type.
Black when $Z_{\mathrm{dr}}$ is $<0 \mathrm{~dB}$, which is omitted from the classification procedure. 


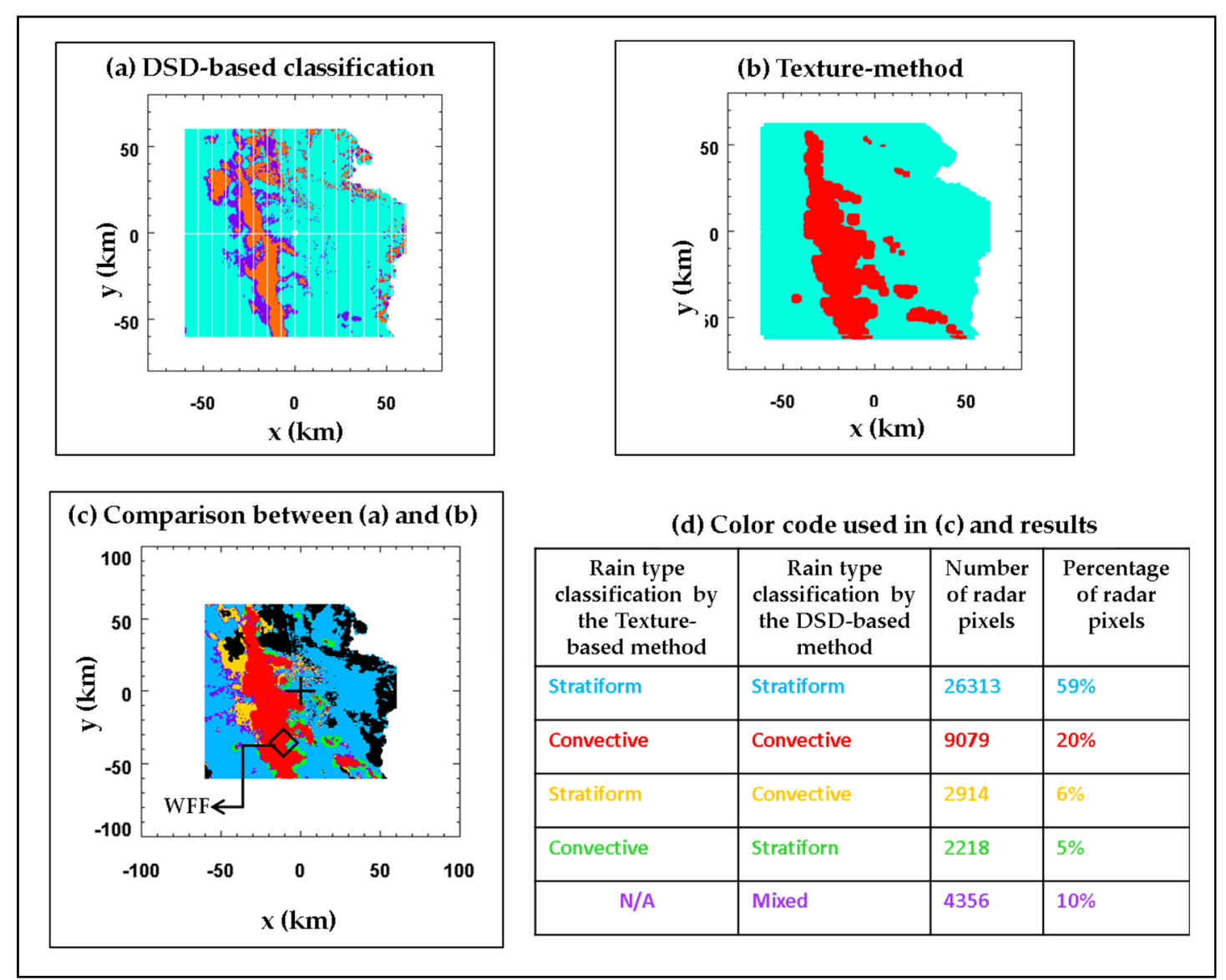

Figure 3. (a) DSD-based rain type classification (orange: convective, cyan: stratiform, purple: mixed); (b) Texture-based classification (red: convective, cyan: stratiform); (c) matched and mismatched rain-types (see text for details); (d) table summarizing the numbers and percentages of matched and mismatched radar pixels (color-code used in (c)).

In terms of percentage pixels, our comparison resulted in: (a) $56 \%$ of the radar pixels being categorized as stratiform rain by both methods; (b) $21 \%$ as convective rain by both methods; and (c) a further $11 \%$ as the 'mixed' category from the DSD-based method. For the remaining $12 \%$ of the pixels, there was disagreement between the two methods, which largely occurred in regions adjacent to $(b)$.

A small but significant improvement was obtained when co-polar attenuation and differential attenuation were included in the radar-data correction procedures. Although at S-band, the attenuation effects are largely negligible, it was found that for this particular case event, the differential propagation phase shift along certain azimuth angles (e.g., $220^{\circ}$ ) were sufficiently high to cause around $0.5 \mathrm{~dB}$ co-polar attenuation beyond the line convection. After applying the correction procedures, it was found that (a) $59 \%$ of the radar pixels were categorized as stratiform rain by both methods; (b) $20 \%$ as convective rain by both methods; and (c) a further $10 \%$ as the 'mixed' category from the DSD-based method. The percentage of 'mismatched' pixels reduced from $12 \%$ to $11 \%$.

One of the main uses of the DSD-based separation technique is that it enables the ratios of the stratiform rain volume to convective rain volume to be determined from the gridded data. Such an analysis is very important from the viewpoint of latent heat estimation, since convective and stratiform rain have different heating rates [17]. Furthermore, since large-scale numerical weather prediction models assume different ratios of convective to stratiform area and rain volume, the retrieved products demonstrated here will form an important validation tool. 


\section{CFADs}

Contoured Frequency-by-Altitude Diagrams (CFADs; [18]) are useful for examining vertical structures. For the Figure 2 case event, these were constructed separately for stratiform and convective rain regions (after applying the DSD-based separation), as well as for mixed precipitation. They are shown in Figure 4. The left panels show the reflectivity contours and the right panels show the differential reflectivity contours. One important aspect to note is that for convective rain (middle panels), both $Z_{h}$ and $Z_{d r}$ decrease from 3 down to $1 \mathrm{~km}$, which in turn indicates that drop break-up is the dominant process [19]. On the other hand, for stratiform rain (top panels), $Z_{h}$ is almost uniform from 3 to $1 \mathrm{~km}$ a.g.l. but $Z_{d r}$ decreases, indicating, once again, the possible occurrence of drop break process but also indicating an increase in number concentration (per unit volume). These features were also observed in the stratiform rain regions of the outer rain-bands of Category-1 Hurricane Dorian (again over Wallops; [20]). A 1D MonteCarlo microphysical model using the super-particle concept (named McSnow; [21]) together with radiosonde data as model input also showed the importance of drop break-up even in light to moderate rain rates, being consistent with the radar observations [20].

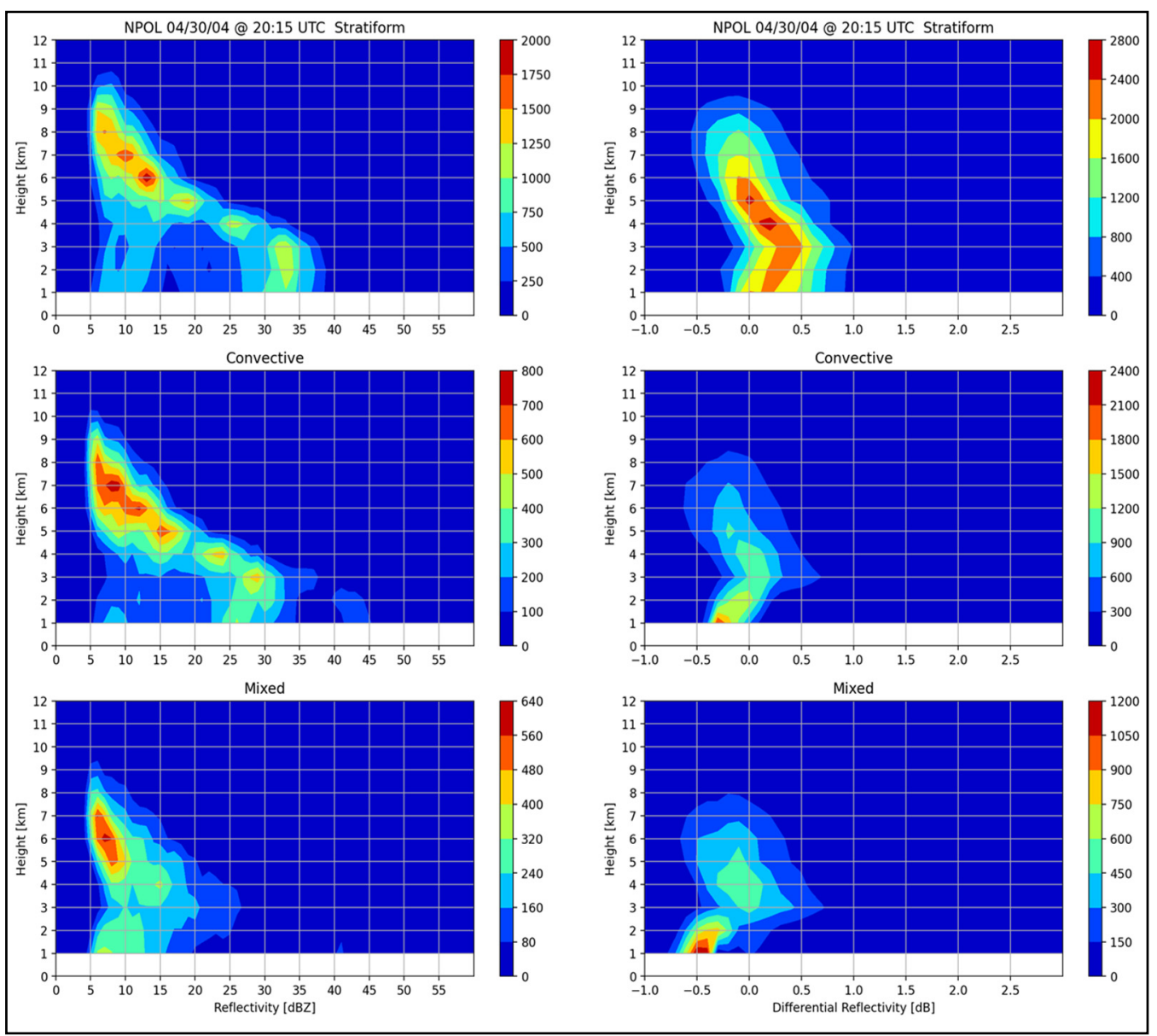

Figure 4. 2D histograms of Reflectivity (left panels) and Differential Reflectivity (right-panels) as a function of height [km], for stratiform rain (top panels), convective rain (middle panels), and mixed (bottom panels).

The corresponding CFADs for $N_{W}$ and $D_{m}$ are shown in Figure 5. The freezing height on this day was at around $3 \mathrm{~km}$; hence, the retrieved $N_{W}$ and $D_{m}$ should be neglected above this height. In the rain region below, one main feature to be noted is that for both stratiform and convective rain, $D_{m}$ decreases from 3 to $1 \mathrm{~km}$, but for the latter, the rate of decrease (with decreasing height) is noticeably higher, indicating that the break-up is more severe. For mixed precipitation, the rate of decrease is more similar to that for convective rain. 


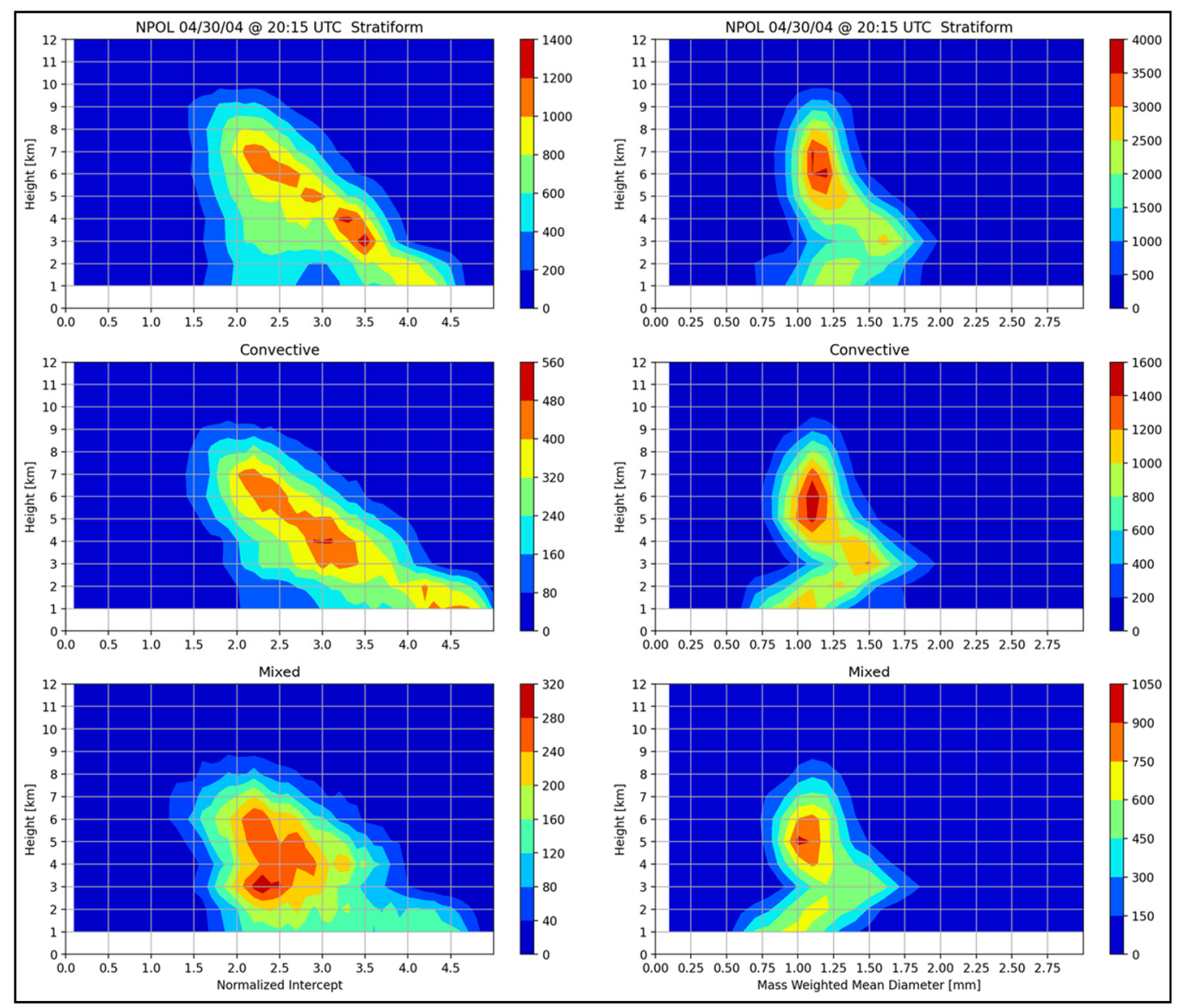

Figure 5. 2D histograms of $N_{W}$ (left panels) and $D_{m}$ (right-panels) as a function of height [km], for stratiform rain (top panels), convective rain (middle panels), and mixed (bottom panels).

\section{Summary}

The case study considered here (of line convection embedded within a larger system) has clearly shown that there is considerable agreement between the texture-based method in [1] and the DSD-based method in [6,8]. Only $12 \%$ of the gridded radar data pixels showed a classification mismatch. When a simple attenuation-correction method (based on differential propagation phase shift) was applied to the S-band data, the percentage of mismatch reduced to $11 \%$.

The DSD-based method utilized previously derived retrievals for the two DSD parameters $N_{W}$ and $D_{m}$. Stratiform and convective rain was based on where the $N_{W}-D_{m}$ points lay in relation to the well-established separation line. Although the separation line was determined based on disdrometer data, we have shown that it can also be used for the gridded S-band NPOL radar data. A third category was also introduced to represent the mixed region. They tended to be in areas immediately surrounding the convective rain regions.

Contoured Frequency-by-Altitude Diagrams (CFADs) were also generated for the stratiform and convective rain separately. They indicate drop break-up to be a dominant process in the rain region below the freezing height. The rate of decrease (with decreasing height) of $D_{m}$ was higher in the case of convective rain, implying that the drop break-up is more severe.

One caveat of the DSD-based technique is that there are a number of error sources which need to be considered when applying this technique. These include (i) radar measurement errors; (ii) retrieval algorithm errors (for example the scatter seen in Figure 1); and (iii) small uncertainties in the assumed separation line. Out of these, (i) is likely to be the most significant source of error. Nevertheless, from this case study, it seems likely that 
the DSD-based technique can be used for the S-band NPOL gridded data with reasonable accuracy. Furthermore, it can be applied not just to the lowest gridded data but also to higher altitudes, i.e., up to the nominal freezing height.

Author Contributions: Conceptualization, M.T., V.B., and D.W.; methodology, D.W. and M.T.; investigation, All Authors; resources, D.W.; data curation, D.M.; assistance, C.P.; writing-original draft preparation, M.T.; writing-review and editing, D.M. and V.B.; project administration, D.W.; funding acquisition, V.B. All authors have read and agreed to the published version of the manuscript.

Funding: This research was funded by NASA's Precipitation Measurement Mission via Grant Award Number 80NSSC19K0676 (MT) and 80NSSC20K0893 (VNB).

Data Availability Statement: Data can be made available upon request to any of the authors.

Conflicts of Interest: The authors declare no conflict of interest. The funders had no role in the design of this study; in the collection, analyses or interpretation of its data; in the writing of this manuscript, and in the decision to publish these results.

\section{References}

1. Steiner, M.; Houze, R.A.; Yuter, S.E. Climatological Characterization of Three-Dimensional Storm Structure from Operational Radar and Rain Gauge Data. J. Appl. Meteor. 1995, 34, 1978-2007. [CrossRef]

2. Tokay, A.; Short, D.A. Evidence from Tropical Raindrop Spectra of the Origin of Rain from Stratiform versus Convective Clouds. J. Appl. Meteor. 1996, 35, 355-371. [CrossRef]

3. Leary, C.A.; Houze, R.A., Jr. The Structure and Evolution of Convection in a Tropical Cloud Cluster. J. Atmos. Sci. 1979, 36, 437-457. [CrossRef]

4. Williams, C.R.; Ecklund, W.L.; Gage, K.S. Classification of precipitating clouds in the Tropics using 915-MHz wind profilers. J. Atmos. Ocean. Technol. 1995, 12, 996-1012. [CrossRef]

5. Atlas, D.; Ulbrich, C.W.; Marks, F.D., Jr.; Black, R.A.; Amitai, E.; Willis, P.T.; Samsur, C.E. Partitioning tropical oceanic convective and stratiform rains by draft strength. J. Geophys. Res. 2000, 105, 2259-2267. [CrossRef]

6. Bringi, V.N.; Williams, C.R.; Thurai, M.; May, P.T. Using dual-polarized radar and dual-frequency profiler for DSD characterization: A case study from Darwin, Australia. J. Atmos. Oceanic Technol. 2009, 26, 2107-2122. [CrossRef]

7. Thurai, M.; Gatlin, P.N.; Bringi, V.N. Separating stratiform and convective rain types based on the drop size distribution characteristics using 2D video disdrometer data. Atmos. Res. 2016, 169 Pt B, 416-423. [CrossRef]

8. Thurai, M.; Bringi, V.N.; May, P.T. CPOL radar-derived drop size distribution statistics of stratiform and convective rain for two regimes in Darwin, Australia. J. Atmos. Ocean. Technol. 2010, 27, 932-942. [CrossRef]

9. Penide, G.; Kumar, V.; Protat, A.; May, P.T. Statistics of drop size distribution parameters and rain rates for stratiform and convective precipitation during the north Australian wet season. Mon. Weather Rev. 2013, 141, 3222-3237. [CrossRef]

10. Wolff, D.B.; Marks, D.A.; Petersen, W.A. General Application of the Relative Calibration Adjustment (RCA) Technique for Monitoring and Correcting Radar Reflectivity Calibration. J. Atmos. Ocean. Technol. 2015, 32, 496-506. [CrossRef]

11. Thurai, M.; Bringi, V.; Wolff, D.; Marks, D.; Pabla, C. Testing the Drop-Size Distribution-Based Separation of Stratiform and Convective Rain Using Radar and Disdrometer Data from a Mid-Latitude Coastal Region. Atmosphere 2021, 12, 392. [CrossRef]

12. Baumgardner, D.; Kok, G.; Dawson, W.; O'Connor, D.; Newton, R. A new ground-based precipitation spectrometer: The Meteorological Particle Sensor (MPS). In Proceedings of the 11th Conference on Cloud Physics, Ogden, UT, USA, 3-7 June 2002; pp. 3-7.

13. Schoenhuber, M.; Lammer, G.; Randeu, W.L. One decade of imaging precipitation measurement by 2D-video-distrometer. Adv. Geosci. 2007, 10, 85-90. [CrossRef]

14. Schönhuber, M.; Lammer, G.; Randeu, W.L. The 2D-Video-Distrometer. In Precipitation: Advances in Measurement, Estimation and Prediction; Michaelides, S., Ed.; Springer: Berlin/Heidelberg, Germany, 2008; pp. 3-31. ISBN 978-3-540-77654-3.

15. Lee, G.; Zawadzki, I.; Szyrmer, W.; Sempere-Torres, D.; Uijlenhoet, R. A General Approach to Double-Moment Normalization of Drop Size Distributions. J. Appl. Meteor. 2004, 43, 264-281. [CrossRef]

16. Ulbrich, C.W.; Atlas, D. Radar Measurement of Rainfall with and without Polarimetry. J. Appl. Meteorol. Climatol. 2008, 47, 1929-1939. [CrossRef]

17. Tao, W.; Iguchi, T.; Lang, S. Expanding the Goddard CSH Algorithm for GPM: New Extratropical Retrievals. J. Appl. Meteor. Climatol. 2019, 58, 921-946. [CrossRef] [PubMed]

18. Yuter, S.E.; Houze, R.A. 3-Dimensional kinematic and microphysical evolution of Florida cumulonimbus: 2. Frequencydistributions of vertical velocity, reflectivity, and differential reflectivity. Mon. Weather Rev. 1995, 123, 1941-1963. [CrossRef]

19. Carr, N.; Kirstetter, P.E.; Gourley, J.J.; Hong, Y. Polarimetric Signatures of Midlatitude Warm-Rain Precipitation Events. J. Appl. Meteorol. Climatol. 2017, 56, 697-711. [CrossRef] 
20. Bringi, V.; Seifert, A.; Wu, W.; Thurai, M.; Huang, G.-J.; Siewert, C. Hurricane Dorian Outer Rain Band Observations and 1D Particle Model Simulations: A Case Study. Atmosphere 2020, 11, 879. [CrossRef]

21. Brdar, S.; Seifert, A. McSnow: A monte-carlo particle model for riming and aggregation of ice particles in a multidimensional microphysical phase space. J. Adv. Model. Earth Syst. 2018, 10, 187-206. [CrossRef] 